\title{
Educational assortative mating in the United States and the effect on income inequality by household from 1960 to 2005
}

\author{
Kathryn Swierzewski \\ Department of Economics, College of Management and Economics, University of Guelph, Guelph, ON Canada. Faculty supervisor: Louise Grogan. \\ For correspondence, please email: swierzkt@mcmaster.ca.
}

\section{Abstract}

This study examines the effect assortative mating by education has on income inequality by household. In contrast to the majority of other literature in this field which focus on the United States (U.S.) as a whole, this study makes use of statelevel data to examine the marriage mating market with respect to education attainment. It also examines how homogamous partnerships increase income inequality across households by analyzing changes in the Gini coefficient over time. Panel data for this analysis is from the U.S. Bureau of Economic Analysis and the Integrated Public Use Microdata Series (IPUMS-International and IPUMS-USA) from the U.S. Census of the Population. Assortative mating by education is shown in this analysis to be a contributing factor to increasing inequality among homogamous heterosexual partnerships in the U.S. from 1960 to 2005.

Keywords: assortative mating; education level; United States (state-level, from 1960-2005); income inequality (household); labour economics; welfare economics

\section{Introduction}

Educational assortative mating has become a topic of increasing importance in welfare and labour economics over the past few decades. There has been increasing income inequality resulting from marriage market mating due to individuals' abilities to choose if, when, and with whom they will enter into marriage. Mare, in two separate studies, and Schwartz noticed increases in educational homogamy over time generated by decreasing intermarriage among groups of relatively well-educated individuals [1,2]. Blau and Smits et al. observed increases in income inequality in the U.S. that may have reduced the likelihood of educational intermarriage by increasing economic and social distances between education groups $[3,4]$. These barriers are partially due to the fact that finding a prospective spouse is more likely at higher levels of schooling than at lower levels.

The present study analyzes the effect of the relationship between educational assortative mating and income inequality by household from 1960 to 2005 in the U.S. This is done by examining the effects of homogamy within educational groups, and analyzing implications on income inequality by comparing Gini coefficients at the state level. This is similar to the methodology of Fortine and Schirle and $\mathrm{Lu}$ et al. and their use of Gini coefficients on Canadian and U.S. data, but the present study makes use of state-level data as opposed to data pertaining to the country as a whole $[5,11]$.

In similar studies by Kalmijn, Mare, and Mare and Schwartz, recent contracted partnerships and newlyweds were analyzed $[1,2,6]$. The present study steps away from this approach as it can cause bias; for example, individuals have the choice and opportunity to attend school after marriage. Looking solely at newlywed partnership patterns would not take into consideration the number of people who upgrade their degree later in life. Instead, the present study focuses on marriages and cohabitating partnerships, since it is believed that individuals go through the same sort of screening process in finding a long-term partner as they do in finding a spouse.

$\mathrm{Lu}$ et al. noted in their analysis that there has been a trend in highly educated women marrying down (hypogamy) [5]. The present study does not examine partnership patterns of those who have attained a Bachelor's degree level of education or higher. Rather, it groups higher levels of education attainment together under the university category. It investigates what is happening at all levels of education from less than primary schooling completed to university completed - and looks at the effects assortative mating by education has on income inequality by household. 


\section{Educational assortative mating in the U.S. and the effect on income inequality by household (Swierzewski)}

In their study, Daly and Valetta noted increases in the proportion of heads of families who were unmarried women and concluded that this could be having an effect on increasing family earnings inequality [7]. Social norms have been altered through time; society is now more accepting of partnerships out of wedlock. Women are also increasingly likely to pursue more advanced levels of education and to partake in the labour force, which has resulted in shifting family dynamics [7]. For example, the socially accepted role of a female is now more likely to resemble that of a male head of household than in previous decades, and women are also increasingly self-reliant from an economic standpoint. Rose and Qian noticed a marriage decline among women over time; since women are no longer as reliant on a spouse for economic stability, they are more concerned with the quality of a potential spouse [8,9]. This trend could also, in part, be attributed to the findings of Juhn, who noticed that the number of less-educated men between the ages of 20 to 24 who are unemployed or not enrolled in school had been on the rise since 1970. Ultimately, this is a less attractive quality to females in the marriage market [10]. In a separate study, Rose noticed an increase in the number of divorces in recent years, resulting in a greater number of lone parents [8]. Consequently, the present study examines statistics of unmarried males and females (never married, divorced, or widowed) to see if there has been a change in single statistics over time that could be contributing to income inequality.

Mare and Schwartz and Qian used crossing models, which determine educational differences between partners that are serious barriers to intermarriage, and used this model to analyze the difficulties that people face in finding a partner with a different education level than their own [2,9]. This can in part be attributed to the fact that people tend to find a spouse while in school, given that school can act as a mating market that brings compatible people together. The present study does not address issues of barriers in the marriage market, but rather assumes such barriers exist.

Assortative mating by education is of importance because it is thought to cause higher levels of income inequality across a country. Stating that there is an increase in inequality is not sufficient - increasing inequality is a crucial topic that needs addressing through policy intervention. Policy suggestions that could potentially aid in correcting the income inequality problem in the U.S. are provided at the end of this study.

\section{Data Collection and Analysis}

\section{Sources of data}

The Integrated Public Use Microdata Series data sets (IPUMS-International and IPUMS-USA) from the U.S. Census of Population and Housing from the U.S. Census Bureau were used in this analysis from 1960 to 2005 in 10year intervals (except from 1990-2005, which was a 15-year interval) $[12,13]$. IPUMS supplies the micro data for $1 \%$ harmonized samples of the population census, organized by household. The majority of the data used were from IPUMSInternational and harmonized across countries, which enables the results of this analysis to be compared to that of other counties in future studies. IPUMS data on the U.S. is not standardly weighted across years. For all 50 states, the data were collected on April $1^{\text {st }}$ for $1960-1990$, and on July $1^{\text {st }}$ for 2005. The unemployment variable was generated using data from IPUMS-USA.

Concerning theIMPUS data sets, the long form of the census was administered differently for all years of the data. In 1960, the long form census was given to every fourth enumeration unit; in 1970, the long form census was given to 1 out of every 5 households with $15 \%$ of the population receiving type one of the census and 5\% receiving type two of the census. For the 1980 and 1990 data, one half of all housing units were required to fill out the long form census in areas with populations under 2,500, and one sixth of the population in all other areas. Finally, data from 2005 was received from the census administered to one out of every one hundred households. The definition of what constitutes a household varied from year to year, but does not affect the present analysis. Broadly, households were defined as dwelling places not including institutions and transient quarters. Households in the 1960, 1970, and 1980 censuses were defined as five or fewer people unrelated to the head of household; in 1990, they were defined as ten or fewer people unrelated to the head; and in 2005 , there was not a restriction imposed on the number of unrelated persons.

The gross Domestic Product (GDP) was acquired through the U.S. Bureau of Economic Analysis where data is collected through federally-administered surveys.

\section{Educational attainment and assortative mating}

When looking at married and cohabitating partnerships, the sample was restricted to households containing one heterosexual couple with both individuals between 18 to 65 years of age. More than one couple living in a household would cause bias and increase the level of inequality observed because income would be pooled and living costs such as property taxes, hydro, water, gas, and groceries would be split among residents of the household. Similarly, taking into consideration same-sex partnerships could also lead to bias due to a gender differential in the labour market in terms of potential earnings. Only a small portion of partnerships in the U.S. are reported to be same sex in the census data (less than $0.5 \%$ ), so eliminating them from the analysis is unlikely to skew results.

For the purpose of looking at education attainment of males and females in heterosexual relationships, the variable analyzed was the categorical variable "edattan", which was used to group people into the following categories: less than primary education completed, primary education completed, secondary schooling completed, and university degree completed. This variable is a good indicator for the general level of education in a sample but is not detailed enough to 
Table 1. Assortative mating of males and females in heterosexual relationships by education in a) 1960 and b) 2005 .

a.

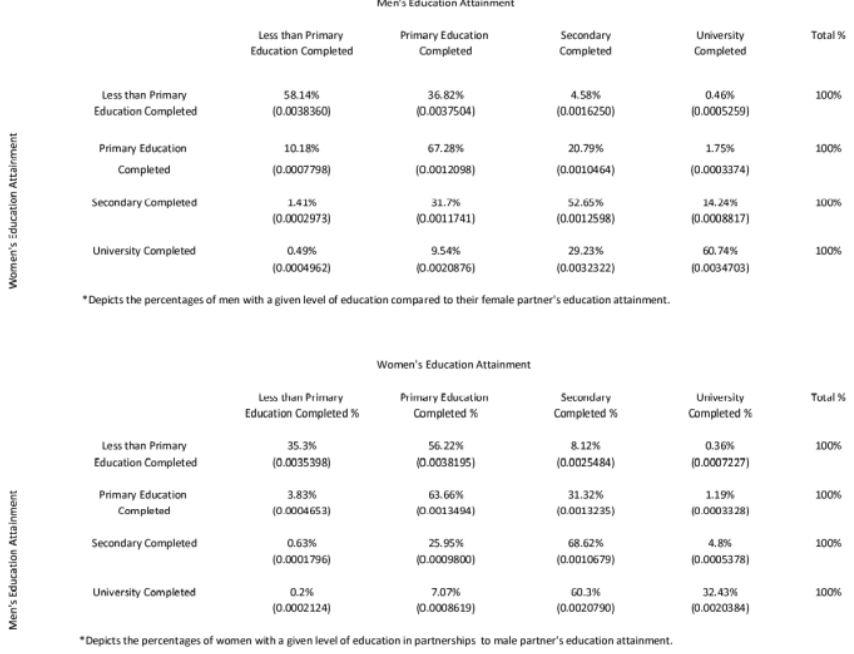

give insight into the dispersion of education at the top end of the education distribution.

Tables 1a and 1b show the joint distribution of men's and women's education attainment, the former table for 1960 data, and the latter table for 2005 data. Similar data exists for 1970, 1980, and 1990, but is not shown here. Collectively, these data show that for each year, the majority of partnerships are with a partner of the same level of education; thus, there is strong evidence of homogamy by education for all years assessed in this study.

While homogamy is present, there are still a large number of males partnering outside of their education level. In $1960,56 \%$ of men with primary education completed partnered with females with less than primary education completed. This indicates heterogamy with respect to men's education (men marrying down) at the bottom end of the education distribution. In the same year, $60 \%$ of men who completed secondary school partnered with women who obtained a university degree. This indicates heterogamy at the top end of the education distribution (men marrying up). Data from other years also depicts a similar relationship: men tend to marry down at the bottom end of the education distribution, but tend to marry up at the top.

While there is still a considerable amount of marrying up present, data for 1980, 1990, and 2005 show that homogamy by education seems to be increasing over time. In 2005, homogamy at the top end of the education distribution is more noticeable than in other years. The percentage of males and females finding a partner outside of their education level is considerably lower than in 1960. Findings suggest that not only is homogamy more prevalent in more recent years, people are also choosing to obtain higher levels of education. Trostel notes a link between higher education and earning potential [14]. This link combined with assortative mating by education creates potential for higher household earnings, b.

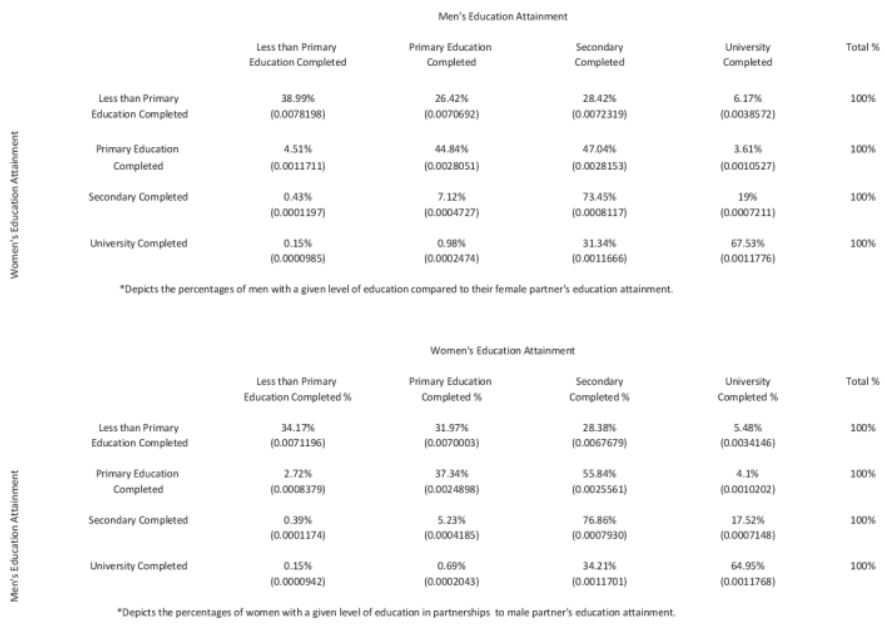

and thus a greater gap between households with higher and lower levels of education attainment. This relationship will be looked at in greater detail later in this study.

\section{Income differences between males and females}

After looking at marriage patterns of female and male partnerships with respect to education attainment, the percentage of women earning 1.5 times or greater than their partner's salary, approximately equal to their partner's salary (defined as being between 0.5 times and 1.5 times the partner's salary), and 0.5 times or less than their partner's salary were examined by cohort (Table 2).

Table 2. Relative salaries of females as compared to their husbands' salaries (\%) by cohort.

\begin{tabular}{|c|c|c|c|c|}
\hline Year & $\begin{array}{l}\text { Wife Salary } 1.5 \text { Times or } \\
\text { More Husband Salary }\end{array}$ & $\begin{array}{l}\text { Wife Salary Approx Equal } \\
\text { to Husband Salary* }\end{array}$ & $\begin{array}{l}\text { Wife Salary } 0.5 \text { Times or } \\
\text { Less Husband Salary }\end{array}$ & Total \\
\hline 1960 & $\begin{array}{c}7.02 \% \\
(0.0004215)\end{array}$ & $\begin{array}{c}23.92 \% \\
(0.0007037)\end{array}$ & $\begin{array}{c}69.06 \% \\
(0.0007626)\end{array}$ & $100 \%$ \\
\hline 1970 & $\begin{array}{c}7.61 \% \\
(0.0004176)\end{array}$ & $\begin{array}{c}23.21 \% \\
(0.0006652)\end{array}$ & $\begin{array}{c}69.18 \% \\
(0.0007275)\end{array}$ & $100 \%$ \\
\hline 1980 & $\begin{array}{c}10.34 \% \\
(0.0004563)\end{array}$ & $\begin{array}{c}26.81 \% \\
(0.0006639)\end{array}$ & $\begin{array}{c}62.85 \% \\
(0.0007242)\end{array}$ & $100 \%$ \\
\hline 1990 & $\begin{array}{c}12.91 \% \\
(0.0005082)\end{array}$ & $\begin{array}{c}33.83 \% \\
(0.0007172)\end{array}$ & $\begin{array}{c}53.26 \% \\
(0.0007563)\end{array}$ & $100 \%$ \\
\hline 2005 & $\begin{array}{c}17.53 \% \\
(0.0005236)\end{array}$ & $\begin{array}{c}32.6 \% \\
(0.0006455)\end{array}$ & $\begin{array}{c}49.87 \% \\
(0.0006886)\end{array}$ & $100 \%$ \\
\hline
\end{tabular}

*Approximately equal defined within the salary interval of 0.5 to 1.5 times that of the husband's salary. 
Table 3. Single and never-married, divorced, spouse-absent, and widowed males and females in the U.S. per cohort (\%) between a) 18 to 65 years of age and b) 24 to 35 years of age.

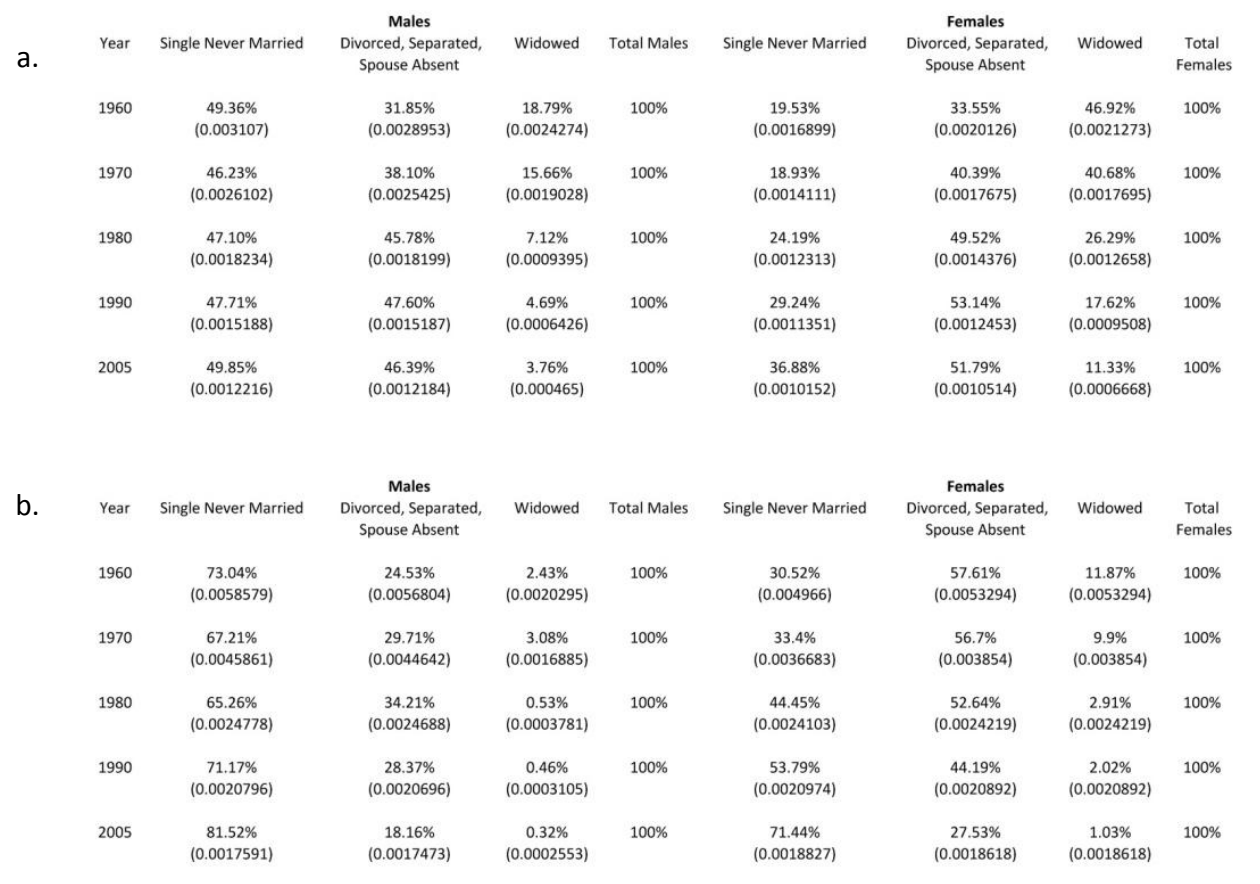

Over time, women's salaries appear to be approaching men's salaries, though men continue to make considerably more, even in recent years. In 1960, 69\% of women made 0.5 times their husband's salary or less, compared to $50 \%$ in 2005 . In 1960 , only $7 \%$ of women earned 1.5 times their husband's salary or greater but in 2005 , this percentage increased to $18 \%$. Bias exists in the statistics at both ends of the distribution (i.e. where women are earning 1.5 times their husband's salary or greater and where women are earning 0.5 times their husband's salary or less) because the statistics shown also take into account individuals who are not working. In earlier years, it was a social norm for women to be stay-at-home wives and for men to be the primary breadwinners of the household whereas in later years, stay-at-home fathers with working wives have become more prevalent. Given the data set, there is no way to tell which individuals are unemployed and searching for work, and which have made the choice to be stay-at-homeparents and to not partake in the workforce.

\section{Singles statistics}

Singles statistics are important to analyze because they help in understanding individuals' partner preferences and how these may have changed over time. Examining whether there is an increased number of single individuals at an older age helps give insight into determining what factors are contributing to the changing marriage market.

For the purpose of analyzing singles statistics of males and females, the sample was first restricted to males and females not in a relationship between the ages of 18 to 65. Table 3a depicts summary statistics of single males and females from 18 to 65 years of age by cohort, significant within a $99 \%$ confidence interval. The table shows that the percentage of single, never-married males has remained relatively constant from 1960 to 2005 , while the percentage of single, never-married females has increased from $20 \%$ in 1960 to $37 \%$ in 2005 . The percentage of males who are divorced, separated, or have a spouse who is absent has increased by $15 \%$ from 1960 to 2005 , whereas for females, the percent increase was $19 \%$. Conversely, the number of widowed females has fallen drastically over the years - in $1960,47 \%$ of females were widowed whereas in 2005 , this percentage was only $11 \%$. There has also been a considerable decrease in the number of widowed men - in 1960, $19 \%$ of men were widowed, whereas in 2005 , only $4 \%$ were widowed.

In a second analysis, the single men and women sample was restricted to individuals between 24 and 35 years of age, since the majority of people within this age group tend to be entering into partnerships with the opposite sex. Table $3 \mathrm{~b}$ shows that the number of single, never-married males between 24 and 35 years of age increased from $73 \%$ in 1960 to $82 \%$ in 2005 , while the number of single, nevermarried females between 24 and 35 years of age increased from $31 \%$ in 1960 to $72 \%$ in 2005 . The percentage of those divorced, separated, or with an absentee spouse decreased by $6 \%$ for males and by $30 \%$ for females between 1960 and 2005. There was also a notable decrease in the percentage of the population between 24 and 35 years who were widowed 


\section{Educational assortative mating in the U.S. and the effect on income inequality by household (Swierzewski)}

the number of widowed males dropped from $25 \%$ in 1960 to $0.32 \%$ in 2005 , and the number of widowed females dropped from $12 \%$ in 1960 to $1 \%$ in 2005 .

Collectively, singles statistics show that women and men are staying single longer and those that do marry are more prone to divorce, separate, or have an absentee spouse than at any other time in history. In addition, there are a decreasing number of marriages lasting until ages where widowing would commonly occur. Increasing age of marriage can be attributed to several factors including increasing pressure to complete higher levels of education and later entry into the work force, as well as higher numbers of women pursuing an education and entering into the workforce. The latter factor results in lowered dependency of women on a spouse for financial support and raised expectations for what constitutes a good mate. Although there does not seem to be a shortage of single males statistically, it seems that women are increasingly searching for spouses with higher levels of educational attainment. This is supported by data which indicates that males with lower levels of education stay single for longer periods of time.

\section{Independent variables}

The effect of educational assortative mating on income inequality by household was assessed in this study using fixed effects. There are six main variables of interest: mean women's education attainment, mean household earnings, state-level Gross Domestic Product, state-level unemployment rate, state-level mean household ownership, and a time trend variable.

The mean women's educational attainment variable was created to determine the causal effect of assortative mating on income inequality at the state level. This variable is the percentage of the mean number of women in heterosexual partnerships in a particular state that have the same or greater level of education as their partner expressed as a decimal ranging in value from 0 to 1 . The mean education level of women relative to that of their partners was fairly constant over time and by state - in 1960, the mean value of women having obtained an education equal to or higher than that of her spouse was 0.82 . This only increased slightly to 0.85 by 2005. This small change in mean can be attributed to the fact that in earlier years, it was more common for both males and females to have attained lower levels of education, but over time, higher education has become increasingly prevalent. The high value of the mean women's education attainment variable in both 1960 and 2005 indicates that there are not a lot of women in the samples who have lower education levels than their partners. This suggests that institutes of higher education act as filters in the marriage market and can help individuals with similar levels of education find compatible spouses.

The mean household earnings variable is an unweighted variable that was created by considering households containing a single heterosexual couple. It is equal to the sum of the couple's earnings and all other partnership earnings including government transfers in the state divided by the number of households in the state sample:

$$
\overline{\text { mnhhearn }}_{s t}=\frac{\sum_{1}^{n}\left(x_{m i}+x_{f i}\right)_{t}+\cdots+\left(x_{m n}+x_{f n}\right)_{t}}{n_{t}}
$$

where $x_{m i}$ and $x_{f i}$ represent income earned by males and females respectively in heterosexual partnerships within a particular state during a particular year (1960, 1970, 1980, 1990, or 2005). This variable does not take into consideration a child or teen residing at their parents' residence and their income contribution to the household. Mean household earnings in the U.S. have changed considerably over time; in 1960 , the mean annual household income was USD 4,872.60, as compared to USD 9,440.90, USD 19,455, USD 36,572.40, and USD 68,508.30 in 1970, 1980, 1990, and 2005, respectively. Although these income levels are in nominal dollars, this does not affect analysis due to the presence of a time trend dummy variable.

Gross Domestic Product "GDPstate" is a variable that represents the market value of all final goods and services at the state level. This is an important variable in measuring the overall well-being of a state because it acts as an indicator of standard or living.

The unemployment rate variable is calculated by taking the number of unemployed people in a state and dividing this value by the total number of individuals capable of being in the labour force. This variable was generated from IPUMS-USA data and is a raw variable not weighted or corrected for specific factors in the economy that the Bureau of Labour Statistics generally accounts for. Unemployment rate captures the standard of well-being of a state. This variable is somewhat correlated with mean household earnings because the greater the number of people reported as unemployed, the lower household earnings tend to be.

The percentage of the mean number of households in a particular state in a given year that own their own residence is a variable expressed as a decimal ranging in value from 0 to 1 . More households own their own residence in recent years of analysis as compared to earlier years. In 1960, the percentage of the mean number of households in a particular state who owned a residence (expressed as a decimal) was 0.67, compared to 0.87 in 2005. There is some bias associated with this variable because some people with considerably high incomes may choose to rent a residence instead of own one; this is especially true for business professionals who travel. However, such individuals would only account for a small portion of the population. In general, the higher the poverty in a particular state, the less likely households are to own a residence; thus the percentage of the mean number of households that own their own residence is used as a proxy for poverty. There is a small degree of multicollinearity between ownership of residence and unemployment rate. 


\section{Educational assortative mating in the U.S. and the effect on income inequality by household (Swierzewski)}

Finally, a time trend variable is used for each year of the data and is used to capture changes to the level of inequality that can be explained by a change in time.

\section{Dependent variable: the Gini coefficient}

The Gini coefficient dependent variable was created using the ineqdeco command by Stephen Jenkins, which is a Stata routine [15]. The Gini coefficient measures the level of inequality in a given sample. Slight gaps exist in this variable for 1970 data because information for seven of the states was unavailable. For the purposes of this study, the Gini coefficient was calculated at the state level by cohort (Table 4). In 1960, New Hampshire had the lowest Gini coefficient (0.249) and thus the highest level of equality, whereas Mississippi had the highest Gini coefficient (0.416) and thus the highest level of inequality. In 2005, New Hampshire had the lowest Gini coefficient (0.329) and thus the highest level of equality, whereas North Carolina had the highest Gini coefficient (0.421) and thus the highest level of inequality. The overall range of Gini coefficients has increased over the years because the level of income inequality by household has increased in most states. U.S. data from 1960 shows a Gini coefficient of 0.304 for 1960 and 0.392 for 2005 .

\section{Empirical Methodology}

\section{Fixed effects regression}

Regression was used to attempt to explain the increase in inequality measured by the Gini coefficient due to assortative mating ceteris paribus. Increases in the Gini coefficient indicate increases in inequality. The empirical model examines the conditional association of educational assortative mating on income inequality by households at the state level using fixed effects regression analysis that accounts for state-fixed effects. Fixed effects regression is best suited for these data because the model imposes timeindependent effects for each entry that are possibly correlated with the regressors. This study controls for omitted variables in panel data since the omitted variables vary across states but do not change over time. The variable "women's education attainment of equal or greater value than partner's education attainment" shows that as partners are selectively matched based on educational attainment, income inequality results. The general framework used in this analysis is as follows:

where

$$
Y_{s t}=\beta_{1} x_{s t}+\alpha_{s}+\gamma_{t}+\varepsilon_{s t}
$$

$$
\alpha_{s}=\beta_{0}+\beta_{2} z_{s}
$$

\begin{tabular}{|c|c|c|c|c|c|}
\hline & 1960 & 1970 & 1980 & 1990 & 2005 \\
\hline Alabama & 0.35369 & 0.31791 & 0.32935 & 0.35099 & 0.38921 \\
\hline Alaska & 0.33158 & 0.30439 & 0.34935 & 0.35675 & 0.37393 \\
\hline Arizona & 0.29944 & 0.29963 & 0.32731 & 0.36977 & 0.39428 \\
\hline Arkansas & 0.39597 & 0.35066 & 0.33846 & 0.37666 & 0.37679 \\
\hline California & 0.27839 & 0.29567 & 0.32883 & 0.37542 & 0.41793 \\
\hline Colorado & 0.29632 & 0.29795 & 0.31882 & 0.35331 & 0.37116 \\
\hline Connecticut & 0.27141 & 0.27955 & 0.30565 & 0.34270 & 0.41192 \\
\hline Delaware & 0.29035 & NA & 0.31443 & 0.33284 & 0.36531 \\
\hline Florida & 0.33415 & 0.32792 & 0.34610 & 0.37641 & 0.39861 \\
\hline Georgia & 0.35572 & 0.32993 & 0.33338 & 0.35890 & 0.39164 \\
\hline Hawaii & 0.29592 & 0.29303 & 0.32530 & 0.34463 & 0.35258 \\
\hline Idaho & 0.30569 & NA & 0.32861 & 0.35669 & 0.36639 \\
\hline Illinois & 0.26971 & 0.27791 & 0.28945 & 0.34445 & 0.38430 \\
\hline Indiana & 0.27236 & 0.25910 & 0.28509 & 0.31974 & 0.34411 \\
\hline lowa & 0.29700 & 0.30858 & 0.30130 & 0.34265 & 0.33505 \\
\hline Kansas & 0.30804 & 0.30656 & 0.31531 & 0.35699 & 0.36093 \\
\hline Kentucky & 0.34750 & 0.35608 & 0.32963 & 0.37358 & 0.37681 \\
\hline Louisiana & 0.35272 & 0.33302 & 0.32685 & 0.37447 & 0.37424 \\
\hline Maine & 0.28491 & 0.28102 & 0.31735 & 0.33851 & 0.36562 \\
\hline Maryland & 0.29447 & 0.28205 & 0.29964 & 0.32471 & 0.35598 \\
\hline Massachusetts & 0.25818 & 0.27473 & 0.29652 & 0.32910 & 0.36786 \\
\hline Michigan & 0.27353 & 0.27022 & 0.28927 & 0.33781 & 0.36602 \\
\hline Minnesota & 0.29519 & 0.27587 & 0.30594 & 0.35332 & 0.37171 \\
\hline Mississippi & 0.41637 & 0.35326 & 0.35018 & 0.35874 & 0.36419 \\
\hline Missouri & 0.30907 & 0.29976 & 0.31358 & 0.36103 & 0.37602 \\
\hline Montana & 0.29298 & NA & 0.32473 & 0.35719 & 0.37384 \\
\hline Nebraska & 0.31102 & 0.31903 & 0.31764 & 0.33954 & 0.34679 \\
\hline Nevada & 0.26196 & 0.28911 & 0.30985 & 0.34580 & 0.37313 \\
\hline New Hampshire & 0.24883 & 0.24984 & 0.29246 & 0.32161 & 0.32907 \\
\hline New Jersey & 0.27103 & 0.28223 & 0.29738 & 0.34093 & 0.38280 \\
\hline New Mexico & 0.32050 & 0.33002 & 0.33123 & 0.37253 & 0.38586 \\
\hline New York & 0.28613 & 0.30111 & 0.31655 & 0.36027 & 0.42116 \\
\hline North Carolina & 0.35466 & 0.32189 & 0.32333 & 0.34516 & 0.38497 \\
\hline North Dakota & 0.36004 & NA & 0.3478 & 0.34868 & 0.35763 \\
\hline Ohio & 0.26055 & 0.26468 & 0.28129 & 0.32888 & 0.35205 \\
\hline Oklahoma & 0.33356 & 0.31635 & 0.32934 & 0.36894 & 0.38580 \\
\hline Oregon & 0.27062 & 0.28672 & 0.31109 & 0.34878 & 0.37630 \\
\hline Pennsylvania & 0.27357 & 0.26898 & 0.28799 & 0.34186 & 0.37188 \\
\hline Rhode Island & 0.26862 & 0.28697 & 0.27885 & 0.32403 & 0.34963 \\
\hline South Carolina & 0.34800 & 0.33623 & 0.31428 & 0.34178 & 0.37724 \\
\hline South Dakota & 0.36189 & NA & 0.34349 & 0.34827 & 0.36383 \\
\hline Tennessee & 0.35045 & 0.31263 & 0.32964 & 0.35720 & 0.38028 \\
\hline Texas & 0.33622 & 0.32087 & 0.33304 & 0.38900 & 0.40805 \\
\hline Utah & 0.27110 & 0.27062 & 0.30451 & 0.32941 & 0.34938 \\
\hline Vermont & 0.30494 & NA & 0.32212 & 0.32692 & 0.36074 \\
\hline Virginia & 0.33798 & 0.30960 & 0.31994 & 0.34870 & 0.37297 \\
\hline Washington & 0.27031 & 0.26730 & 0.29669 & 0.34319 & 0.36380 \\
\hline West Virginia & 0.31795 & 0.29961 & 0.30201 & 0.35208 & 0.36390 \\
\hline Wisconsin & 0.26712 & 0.25701 & 0.28761 & 0.32952 & 0.33828 \\
\hline Wyoming & 0.27970 & NA & 0.29863 & 0.32831 & 0.33787 \\
\hline United St & 0.30395 & 0.30233 & 0.31684 & 0.36311 & 0.39230 \\
\hline
\end{tabular}

Table 4. Gini coefficients by U.S. state by cohort. 


\section{Educational assortative mating in the U.S. and the effect on income inequality by household (Swierzewski)}

Fixed effects regression analysis assumes that $\alpha_{s}$ is not independent of $z_{s}$ or $x_{s t}$. The variable $\alpha_{s}$ is treated as the unknown intercept that is being estimated for each state in the United States; it is the entry-fixed effect. The variable $x_{s t}$ is the time invariant regressor and $z_{s}$ is the unobserved variable that varies from state to state - for example, statespecific laws, policies, or beliefs. The variable $\gamma_{t}$ is the vector of time dummy variables.

Economic intuition was used to select appropriate independent variables. Women's education attainment equal or greater than the partner's education attainment "meanedsog" is the causal independent variable for assortative mating by education. The greater the percentage of the mean represented as a decimal, the higher a woman's education is relative to her male partner. Higher educational attainment of women as compared to their male partners indicates that assortative mating is present, because individuals view education status as an important determinant in selecting a partner. Mean household earnings of a partnership "mnhhearn" was another potential independent variable. The greater the gap between mean household incomes in a particular state is, the greater the income inequality. This variable was initially used in the fixed effects regression but later dropped due to multicolinearity with mean women's education attainment because higher education is associated with greater returns in terms of earned income in the labour force.

Analysis attempts to control for omitted variable bias by including as many relevant variables as possible in the regression. Economic intuition fueled the following preliminary regression:

$$
\begin{aligned}
\left(\text { Gini }_{s t}-\overline{\text { Ginl }}_{s}\right) & =\beta_{0}+\beta_{1}\left(\text { mnwedsog }_{\text {st }}-\overline{\text { mnwedsog }}_{s}\right) \\
& +\beta_{2}\left(\text { GDPstate }_{\text {st }}-\overline{\text { GDPstate }}_{s}\right) \\
& +\beta_{3}\left(\text { urate }_{s t}-\overline{\text { urate }}_{s}\right) \\
& +\beta_{4}\left(\text { ownship }_{s t}-\overline{\text { ownship }}_{s}\right) \\
& +\beta_{5} \text { yeardummy } \\
& +\beta_{6} \text { yeardummy } \\
& +\beta_{7} \text { yeardummy } \\
& +\beta_{8} \text { yeardummy } \\
& +\beta_{9} \text { yeardummy } \\
&
\end{aligned}
$$

From this regression, the statistical significance of each of the variables and the overall fit of the model (the Rsquared and the F-statistic) were taken into consideration and the fixed effects regression was reformed. A multicolinearity test was conducted, and the regression was amended. After this point, the fixed effects regression was then robust to check for heteroscedasticity. Tests were then conducted to check for serial correlation, endogeneity, as well as the joint significance of the independent variables.

\section{Results and Discussion}

After detecting the presence of heteroscedasticity in the fixed effects model, the regression was corrected and errors

\begin{tabular}{|c|c|c|c|}
\hline Variable & Coefficient & RobustS.E. & t-statistic \\
\hline Mnwedsog & 0.441832 & 0.1106946 & 3.99 \\
\hline GDPstate & $5.20 \mathrm{E}-08$ & $1.43 \mathrm{E}-08$ & 3.65 \\
\hline Urate & -0.0364722 & 0.1409453 & -0.26 \\
\hline Ownship & -0.2324443 & 0.0549787 & -4.23 \\
\hline Year1 & DROPPED & & \\
\hline Year2 & 0.00947809 & 0.0030093 & 3.15 \\
\hline Year3 & 0.0477809 & 0.0075449 & 6.33 \\
\hline Year4 & 0.0668728 & 0.007304 & 9.16 \\
\hline Year5 & 0.0844231 & 0.0110362 & 7.65 \\
\hline Constant & 0.1019391 & 0.0902618 & 1.13 \\
\hline
\end{tabular}
were robust (Table 5). The within $\mathrm{R}$-squared, which is the $\mathrm{R}$ squared from the mean deviation regression, is 0.842 . The intraclass correlation indicates that $67 \%$ of the variance was due to differences across panels. The errors are correlated with the regressors by -0.128 . The F-statistic of the fixed effects model is 7.91 with a p-value of 0 , indicating that the coefficients differ from zero.

Table 5. Regression results with robust standard errors.

The conditional association variable of interest, women's education greater or equivalent to partner's education, has a p-value of 0 and a t-statistic of 3.99. Therefore, this variable is statistically significant with a coefficient of 0.441 , indicating that an increase of 0.1 in the mean number of years of education in a particular state would increase the Gini coefficient by 0.044 ceteris paribus with standard errors of 0.111 . The large value of the coefficient indicates that assortative mating has a substantial and, due to the standard errors, significant role in explaining the Gini coefficient. An interpretation of these results is that as a woman's education level rises to meet and potentially exceed her partner's education level, she is more likely to participate in the workforce (i.e. put her education to use) and thus contribute to a higher household income. Mean women's education equal or greater than that of partner's education is a good variable for measuring assortative mating because it takes into account the fact that both men and women are increasingly pursuing higher levels of education over time by considering the relative difference between men and women's educational attainment. The presence of educational assortative mating in the U.S. is a likely contributor to income inequality. Because men and women with similar education levels are likely to marry, households consisting of a highly educated couple will make, on average, substantially more than households consisting of a couple with a lower level of education. Thus, the income 


\section{Educational assortative mating in the U.S. and the effect on income inequality by household (Swierzewski)}

differential between couples of high versus low education attainment is exemplified.

The variable GDP per state is statistically significant with a t-statistic of 3.65 and a p-value of 0.001 . The beta coefficient of this variable is $5.20 \mathrm{e}-08$, which is very small and indicates that GDP per state does not play a major role in explaining the Gini coefficient's potential value by state, even though it is significant in its determination.

Unemployment rate is not statistically significant with a $\mathrm{p}$-value of 0.797 and a t-statistic of -0.26 . The coefficient is -0.036 which indicates that as unemployment increases in a state, equality will also increase ceteris paribus. This initially seems counterintuitive, but can be explained by the fact that the Gini coefficient measures the level of inequality in a state and does not explain how inequality is distributed. Greater unemployment means that the distribution of income in a particular state is more equal because fewer people are generating an income. Even though this variable is not statistically significant using a $95 \%$ confidence interval, it is intuitively important in explaining income inequality.

The ownership of residence variable is statistically significant with a p-value of 0 and a t-statistic of -4.23 on a $95 \%$ confidence interval. The coefficient for home ownership is -0.232 indicating that an increase of 0.1 in the percentage of the mean number of home ownerships in a state expressed as a decimal would decrease the Gini coefficient by 0.023 ceteris paribus. The more people who own a home in a state there are, the more likely there will be income equality. Because residence ownership is used as a proxy for poverty in this study, more residence ownership implies that there are less people living in poverty. If households are unable to afford home ownership and are forced to rent, then they most likely do not have the income required to own a home.

The time trend dummy variables for 1970, 1980, 1990, and 2005 are all statistically significant ranging in p-values from 0 to 0.003 and t-statistics from 3.15 to 9.16 . These variables make it possible to capture state-specific trends since the time dummy variables capture the difference in inequality that is occurring with respect to time. These variables are extremely important with panel data. The time dummy variable for 1960 was dropped due to multicolinearity. The variable for 2005 can be interpreted as having a positive impact on inequality meaning that assuming the base year for comparison is 1960 , time trend for 2005 accounts for a change in the Gini coefficient by 0.084 all else equal.

Overall, assortative mating in the U.S. by education level appears to explain, by conditional association, income inequality by household. Table 6 shows the effect that women's educational attainment that is the same or higher than that of their partner's educational attainment has on the Gini coefficient in each state, from 1960 to 2005. In Arkansas, Mississippi, and North Carolina, assortative mating has decreased income inequality levels with changes in the Gini coefficient being $-0.008,-0.023$, and -0.001 , respectively. All other states show a positive correlation between educational attainment and income inequality.
Assortative mating has increased income inequality the most in Connecticut, with an increase in the Gini coefficient of 0.062 . Evidently male-female mating by education attainment has contributed to increasing income inequality by household in $94 \%$ of all states within the United States of America, a result that is consistent with the findings of Blau, Kalmijn, Mare, Mare and Schwartz, and Smits et al. [1-4, 6].

Table 6. Effect of assortative mating on change in Gini coefficient by state.

\begin{tabular}{|c|c|c|}
\hline State & $\begin{array}{l}\Delta \text { Mean Women Ed } \\
\text { Attainment Same or } \\
\text { Greater than Partner }\end{array}$ & $\begin{array}{l}\text { Contribution to } \\
\text { Assortative Matching } \\
\Delta \text { in Gini Coefficient }\end{array}$ \\
\hline Alabama & 0.036 & 0.016 \\
\hline Alaska & 0.042 & 0.019 \\
\hline Arizona & 0.095 & 0.042 \\
\hline Arkansas & -0.019 & -0.008 \\
\hline California & 0.140 & 0.062 \\
\hline Colorado & 0.075 & 0.033 \\
\hline Connecticut & 0.141 & 0.062 \\
\hline Delaware & 0.075 & 0.033 \\
\hline Florida & 0.064 & 0.028 \\
\hline Georgia & 0.036 & 0.016 \\
\hline Hawaii & 0.057 & 0.025 \\
\hline Idaho & 0.061 & 0.027 \\
\hline Illinois & 0.115 & 0.051 \\
\hline Indiana & 0.072 & 0.032 \\
\hline lowa & 0.038 & 0.017 \\
\hline Kansas & 0.053 & 0.023 \\
\hline Kentucky & 0.029 & 0.013 \\
\hline Louisiana & 0.022 & 0.010 \\
\hline Maine & 0.081 & 0.036 \\
\hline Maryland & 0.062 & 0.027 \\
\hline Massachusetts & 0.110 & 0.048 \\
\hline Michigan & 0.092 & 0.041 \\
\hline Minnesota & 0.077 & 0.034 \\
\hline Mississippi & -0.052 & -0.023 \\
\hline Missouri & 0.067 & 0.030 \\
\hline Montana & 0.081 & 0.036 \\
\hline Nebraska & 0.036 & 0.016 \\
\hline Nevada & 0.111 & 0.049 \\
\hline New Hampshire & 0.080 & 0.035 \\
\hline New Jersey & 0.112 & 0.049 \\
\hline New Mexico & 0.065 & 0.029 \\
\hline New York & 0.135 & 0.060 \\
\hline North Carolina & 0.030 & 0.013 \\
\hline North Dakota & -0.002 & -0.001 \\
\hline Ohio & 0.092 & 0.040 \\
\hline Oklahoma & 0.052 & 0.023 \\
\hline Oregon & 0.106 & 0.047 \\
\hline Pennsylvania & 0.098 & 0.043 \\
\hline Rhode Island & 0.081 & 0.036 \\
\hline South Carolina & 0.029 & 0.013 \\
\hline
\end{tabular}




\section{Conclusions and Limitations}

The present study shows a conditional association between assortative mating by education and state-level income inequality in the U.S. between 1960 and 2005. Variables of interest include women's level of education attainment equal to or greater than that of their partner, mean household income by state, Gross Domestic Product of each state per year, unemployment rate of each state per year, residence ownership status of each household by state per year, and a time trend variable; however, more explanatory variables are required to fully capture a causal effect. Fixed effects regression analysis of panel data from the U.S. Bureau of Economic Analysis and the U.S. Census of the Population were used to determine conditional association. Statistical significance of the causal variable of interest, women's level of education attainment equal to or greater than that of their partner, as well of other independent variables (except unemployment rate) was shown. The Fstatistic showed joint significance of regressors, indicating that the fixed effects model shows strong conditional association between assortative mating based on education level and income inequality, as measured by the Gini coefficient.

Some limitations exist for the regression analysis conducted in this study. The education attainment variable for men and women only categorized education into four groups. Another variable measuring education was available, but was not consistent for all years of observations. Further research and analysis should be conducted to assess assortative mating patterns at the top end of the education distribution, for example those with Bachelor's, Master's, doctoral, or professional degrees.

Another limitation of this study is that the Gini coefficient only addresses that fact that inequality exists, but says nothing with regards to whether or not there are a large percentage of individuals at the top or bottom ends of the income distribution (i.e. it does not explain how income inequality is distributed). Two states with similar Gini coefficients could have very different income distributions. Further research on this topic is required to analyze how inequality is distributed. In future studies, looking at comparative statistics on the Gini coefficient that compare percentiles of the samples by earnings would be helpful. For example, dividing the average income of the top 5 and $10 \%$ of the population by the average income of the bottom 5 and $10 \%$ would give insight into the distribution of income in each state over time. Further research should also assess how many households in the sample live below the poverty line because in this way, it would be possible to evaluate whether rising inequality is really a problem. If there is an increase in inequality over time but the same number or fewer households living below the poverty line, then is the rising inequality really a problem?
Increasing income inequality due to educational assortative mating is an issue that deserves government attention. Since 1960, income inequality has been on the rise in the U.S., and policy intervention is necessary to mitigate the problem. One policy suggestion is to strengthen the social safety net. This can be done by decreasing the cost of obtaining a post-secondary education, because removing financial barriers from education would increase accessibility and allow more people to pursue a higher education. Another policy option is to strengthen unions. A lot of unions tend to represent workers at the bottom end of the income and education distribution - for example, factory workers. Strengthening these unions can lead to increased wages and worker benefits. Implementing a Pigovian tax to generate negative externalities is another policy worth considering to aid in correcting income inequality. A negative externality is an action of a product on consumers (in this case, higher education) that imposes a negative side effect, or a social cost, on a third party (in this case, lowered income). A Pigovian tax would mean that those who make more money (and presumably, are more educated) would be taxed more than those who do not. However, a limitation of this system is that the tax money generated may not go directly to those citizens who most need it and may instead be used by the government for other purposes that appear to be more pressing. Thus, another option would be to give greater tax breaks to the wealthy for charity donations and positive financial community involvement, because this would have a direct positive effect on decreasing inequality with respect to income.

\section{Acknowledgements}

I wish to thank Fraser Summerfield and Michael Batu for their help in the creation of this paper. I would also like to thank Professor Louise Grogan for her guidance and support throughout the process of constructing this paper.

\section{References}

1. Mare, R.D. (1991). Five decades of educational assortative mating. American Sociological Review, 56, 15-32.

2. Mare, R.D. \& Schwartz, C.R. (2005). Trends in educational assortative marriage from 1940 to 2003. Demography, 42, 621-646.

3. Blau, P.M. (1977). Inequality and Heterogeneity. New York, NY: Free Press.

4. Smits, J., Ultee, W., \& Lammers, J. (1998). Educational homogamy in 65 Counties: an explanation in differences in openness using country level explanatory variables. American Sociological Review, 63, 264-185. 
5. Lu, Y., Morissette, R., \& Schirle, T. (2011). The growth of family earnings inequality in Canada. Income and Wealth, 57, 23-29.

6. Kalmijn, M. (1991). Shifting boundaries: trends in religious and educational homogamy. American Sociological Review, 56, 786-800.

7. Daly, M.C. \& Valetta, R.G. (2006). Inequality and poverty in the United States: the effects of rising dispersion of men's earnings and changing family behavior. Economica, 73, 75-89.

8. Rose, E. (2001). Marriage and assortative mating: how have the patterns changed? Center for Statistics in the Social Sciences at the University of Washington.

9. Qian, Z. (1998). Changes in assortative mating: the impact of age and education, 1970-1990. Demography, $35,279-292$.

10. Juhn, C. (1992). The decline of male labour market participation: the role of declining market opportunities. Quarterly Journal of Economics, 107, 79-121.
11. Fortin, N. \& Schirle, T. (2006). Gender dimensions of changes in earnings inequality in Canada. In Green, D.A. \& Kesselman, J.R. (eds.) Dimensions of Inequality in Canada. Vancouver, BC: UBC Press.

12. Minnesota Population Center. (2011). Integrated Public Use Microdata Series, International: Version 6.1. Minneapolis: University of Minnesota. [Machinereadable database].

13. Ruggles, S., Alexander, T., Genadek, K., Goeken, R., Schroeder, M.B., \& Sobek, M. (2010). Integrated Public Use Microdata Series, Version 5.0. Minneapolis: University of Minnesota. [Machine-readable database].

14. Trostel, P.A. (2010). The impact of new college graduates on instrastate labour markets. Journal of Education Finance, 36, 186-213.

15. Jenkins, S.P. (1999). "INEQDEC0: Stata module to calculate inequality indices with decomposition by subgroup," Statistical Software Components S366007, Boston College Department of Economics, revised 24 Feb 2010. 